\title{
Parâmetros de Fermentação Ruminal em Bovinos Alimentados com Grãos de Milho ou Sorgo de Alta Umidade Ensilados
}

\author{
Roberta Passini ${ }^{1}$, Paulo Henrique Mazza Rodrigues ${ }^{2}$, Ari Luiz de Castro ${ }^{3}$, Antonio Carlos Silveira ${ }^{4}$
}

\begin{abstract}
RESUMO - Os parâmetros de fermentação ruminal de dietas contendo silagem de sorgo úmido em substituição à de milho úmido foram estudados em 12 fêmeas bovinas, com peso médio de $584 \mathrm{~kg}$. O delineamento foi inteiramente casualizado com três tratamentos: substituição do milho úmido pelo sorgo úmido ensilado, nos níveis de 0,50 e $100 \%$. As dietas continham grão úmido de milho ou de sorgo ensilados, soja extrusada, uréia, feno de aveia (Avena sativa sp.), suplemento mineral e monensina. Adicionalmente, foi avaliada a degradabilidade in situ da matéria seca e da fibra em detergente neutro do feno de aveia. Não houve diferença sobre produção total de ácidos graxos voláteis (AGVs) no rúmen, porcentagem molar dos ácidos acético, propiônico e butírico, relação acético/propiônico, pH ruminal, concentração de $\mathrm{N}_{-} \mathrm{NH}_{3}$ no rúmen, fluxo e volume de líquidos do rúmen, nos diferentes tratamentos. A degradabilidade da matéria seca e da fibra em detergente neutro do feno não apresentou diferenças. Não se constatou melhora nos parâmetros de fermentação ruminal com a associação dos grãos.
\end{abstract}

Palavras-chave: degradabilidade, grão úmido, nutrição, rúmen, vacas

\section{Ruminal Fermentation Parameters in Bovines Feeding High Moisture Grain Sorghum or Corn Silages}

\begin{abstract}
Ruminal fermentation parameters of diets containing high moisture sorghum silage in replacement of high moisture corn silage were studied in 12 dry cows ( $584 \mathrm{~kg}$ of BW). A completely randomized design was used with three treatments: high moisture sorghum silage replacing high moisture corn silage at levels of 0,50 , and $100 \%$. Diets contained high moisture corn or sorghum silages, extruded soybean, urea, oat hay (Avena sativa sp.), mineral supplement and monensin. The trial extended for 21 days, the last one used for ruminal sampling at $0,2,4,6,8,10$ and 12 hours after meal. Additionally, in situ degradability of oat hay dry matter and neutral detergent fiber was evaluated. There was not difference in total volatile fatty acids (VFA) production in the rumen, molar percentage of acetate, propionate and butirate, acetate/propionate ratio, ruminal $\mathrm{pH}$, ammoniacal nitrogen $\left(\mathrm{NH}_{3}-\mathrm{N}\right)$ concentration, ruminal liquid turnover and ruminal liquid volume. Degradability of hay dry matter and neutral detergent fiber was not different. No improvement on the ruminal fermentation parameters with the association of grains was observed.
\end{abstract}

Key Words: cows, degradability, high moisture, nutrition, rumen

\section{Introdução}

O emprego de maiores quantidades de grãos de cereais na dieta de bovinos em confinamento baseiase no fato dos mesmos serem ricos em amido, e este ser o principal responsável pela energia necessária para a manutenção e crescimento das bactérias ruminais. Por sua vez, os microorganismos do rúmen, através de suas vias metabólicas de extração de energia, produzem principalmente os ácidos graxos voláteis (AGVs), que, segundo Van Soest (1994), suprem mais de $85 \%$ das exigências energéticas do animal.
Nestes últimos anos, têm sido demonstrado os benefícios do processamento dos grãos de cereais, o que aumenta a digestibilidade ruminal do amido, e com isto, propicia mais energia disponível para o desenvolvimento da população microbiana, resultando em maior produção de AGVs. Entre os processamentos empregados, os químico-físicos, como a floculação ou a ensilagem com alta umidade, têm se mostrado bastante eficientes (Owens, 1997; Zinn, 1990).

Entre os fatores que afetam o crescimento e a eficiência das bactérias ruminais, a energia e a proteína são os principais, contudo, outros fatores contri-

\footnotetext{
${ }^{1}$ Pós-doutoranda, Departamento de Nutrição e Produção Animal, FMVZ/USP. CP 23, CEP: 13.630.970, Pirassununga, SP E.mail: rpassini@bol.com.br

${ }^{2}$ Professor Doutor, Departamento de Nutrição e Produção Animal, FMVZ/USP. CP 23, CEP: 13.630.970, Pirassununga, SP. E.mail: pmazza@usp.br

3 Biomédico, Técnico de Laboratório, Departamento de Nutrição e Produção Animal, FMVZ/USP. CP 23, CEP: 13.630.970, Pirassununga, SP. E.mail:aricastr@usp.br

${ }^{4}$ Professor Titular, Departamento de Nutrição e Melhoramento Animal, FMVZ/UNESP. CP 560, CEP: 18.618.000, Botucatu, SP.
} 
buem com a fermentação ruminal, como o $\mathrm{pH}$ e a taxa de passagem, que por sua vez são determinados pelo nível de consumo, sistema de alimentação, tamanho de partícula, qualidade e proporção do volumoso na dieta total, tipo e processamento dos carboidratos dos alimentos (Van Soest, 1994).

Dessa forma, objetivou-se avaliar o efeito do uso de silagens de grãos úmidos de milho ou de sorgo sobre a concentração de ácidos graxos voláteis no rúmen, $\mathrm{pH}$ ruminal, concentrações ruminais de nitrogênio amoniacal, taxa de passagem de líquidos e volume líquido ruminal e degradabilidade in situ da matéria seca e da fibra em detergente neutro do feno de aveia (Avena sativa sp.).

\section{Material e Métodos}

Um estábulo experimental foi usado como instalação, consistindo de baias, com cochos de cimento individuais e bebedouros automáticos comuns a cada dois animais. Foram utilizadas 12 fêmeas bovinas mestiças holandês x zebu, não lactantes e não gestantes, possuindo em média $584 \mathrm{~kg}$ de peso vivo e portadoras de cânulas ruminais com $10 \mathrm{~cm}$ de diâmetro e $7,5 \mathrm{~cm}$ de espessura. Estas foram distribuídas inteiramente ao acaso nos tratamentos.

Para confecção das silagens de grão úmido, o milho foi colhido na fase de maturação fisiológica, que é caracterizada pelo momento em que cessa a translocação de nutrientes da planta para os grãos, ocasião em que os mesmos apresentam o máximo teor de amido, proteína e óleo, com um teor de umidade médio de $28 \%$. Na prática, este estádio é verificado pela ocorrência da camada preta na base do grão. Independentemente do cultivar e da época de semeadura do milho, a maturação fisiológica sempre ocorre aos 50 dias após a polinização. O sorgo foi colhido na mesma fase de maturação do milho e com um teor de umidade aproximado de $30 \%$. Os grãos foram triturados em uma granulometria de $12 \mathrm{~mm}$, sendo em seguida armazenados em silos do tipo trincheira, por 90 dias. As práticas de carregamento, compactação e vedação do silo foram as mesmas utilizadas para a ensilagem da planta inteira.

As dietas isoprotéicas (11\% PB) foram compostas de grão úmido de milho ou de sorgo ensilados, soja extrusada, uréia, feno de aveia (Avena sativa sp.), suplemento mineral e monensina sódica, balanceadas segundo o NRC (1996). A água permaneceu à vontade durante todo o ensaio. Constam na Tabela 1 as
Tabela 1 - Porcentagem dos ingredientes e composição química das dietas experimentais, com base na matéria seca

Table 1 - Ingredients percentage and chemical composition of the experimental diets, in dry matter basis

\begin{tabular}{|c|c|c|c|}
\hline \multirow[t]{2}{*}{$\begin{array}{l}\text { Ingredientes } \\
\text { Ingredients }\end{array}$} & \multicolumn{3}{|c|}{$\begin{array}{l}\text { Dietas experimentais } \\
\text { Experimental diets }\end{array}$} \\
\hline & S 0 & S 50 & S 100 \\
\hline $\begin{array}{l}\text { Feno de aveia } \\
\text { (Avena sativa sp.) } \\
\text { Oat hay }\end{array}$ & 21,5 & 21,5 & 21,5 \\
\hline $\begin{array}{l}\text { Silagem de milho úmido } \\
\text { High moisture corn }\end{array}$ & 49,6 & 24,8 & - \\
\hline $\begin{array}{l}\text { Silagem de sorgo úmido } \\
\text { High moisture sorghum }\end{array}$ & - & 24,8 & 49,6 \\
\hline $\begin{array}{l}\text { Soja extrusada } \\
\text { Extruded soybean }\end{array}$ & 5,2 & 5,2 & 5,2 \\
\hline $\begin{array}{l}\text { Milho triturado } \\
\text { Cracked corn }\end{array}$ & 21,5 & 21,5 & 21,5 \\
\hline $\begin{array}{l}\text { Uréia } \\
\text { Urea }\end{array}$ & 0,43 & 0,43 & 0,43 \\
\hline $\begin{array}{l}\text { Suplemento mineral } \\
\text { Mineral supplement }\end{array}$ & 1,72 & 1,72 & 1,72 \\
\hline $\begin{array}{l}\text { Rumensim }{ }^{\circledR} \\
\text { Rumensim }{ }^{\circledR}{ }^{1}\end{array}$ & 0,03 & 0,03 & 0,03 \\
\hline $\begin{array}{l}\text { Composição química }(\%) \\
\text { Chemical composition (\%) }\end{array}$ & & & \\
\hline $\begin{array}{l}\text { Matéria seca } \\
\text { Dry matter }\end{array}$ & 81,34 & 82,61 & 83,88 \\
\hline $\begin{array}{l}\text { Proteína bruta } \\
\text { Crude protein }\end{array}$ & 11,25 & 11,09 & 10,92 \\
\hline $\begin{array}{l}\text { Fibra em detergente neutro } \\
\text { Neutral detergent fiber }\end{array}$ & 24,33 & 24,24 & 24,15 \\
\hline $\begin{array}{l}\text { Extrato etéreo } \\
\text { Ether extract }\end{array}$ & 4,20 & 3,91 & 3,61 \\
\hline $\begin{array}{l}\text { Matéria mineral } \\
\text { Mineral matter }\end{array}$ & 4,12 & 4,12 & 4,12 \\
\hline $\begin{array}{l}\text { Carboidratos não estruturais } \\
\text { Non structural carbohydrate }\end{array}$ & 56,10 & 56,64 & 57,20 \\
\hline $\begin{array}{l}\text { Amido } \\
\text { Starch }\end{array}$ & 48,36 & 49,18 & 49,99 \\
\hline
\end{tabular}

${ }^{1}$ Rumensim ${ }^{\circledR}$ - produto comercial que contém 10\% de monensina sódica por quilo do produto.

${ }^{1}$ Rumensim ${ }^{\circledR}$ - commercial product with $10 \%$ of sodium monensin per kilogram of product.

porcentagens dos ingredientes e a composição química das dietas experimentais.

A ração foi fornecida em duas refeições ( 8 e 16 h) na forma de mistura completa, obedecendo à proporção de $20 \%$ volumoso e $80 \%$ concentrado, com base na matéria seca. A quantidade de ração fornecida foi calculada em função do consumo durante o período de adaptação, de forma a existirem $15 \%$ de sobras. Foram coletadas amostras diárias da dieta durante 0 período experimental para posteriores análises bromatológicas, as quais foram realizadas pelo Laboratório de Bromatologia da FMVZ-USP. Matéria 
seca (MS), proteína bruta (PB), extrato etéreo (EE) e matéria mineral (MM) foram avaliados segundo normas da AOAC (1985), e fibra em detergente neutro (FDN) segundo Goering \& Van Soest (1970). A análise de amido foi realizada conforme descrito por Rossi Jr. \& Pereira (1995), procedendo-se à extração dos carboidratos solúveis segundo Hendrix (1993).

O experimento teve duração de 21 dias, sendo os primeiros 16 dias destinados à adaptação dos animais às dietas experimentais. Entre o 170 e $20^{\circ}$ dia, foi avaliada a degradabilidade in situ da MS e FDN do feno. O $21^{\circ}$ dia foi utilizado para a coleta de líquido ruminal, avaliando as concentrações de ácidos graxos voláteis (AGVs), nitrogênio amoniacal (N-NH3), pH ruminal e dinâmica líquida ruminal.

Os tratamentos, com base na mistura completa, foram:

S0: $100 \%$ grão úmido de milho ensilado;

S50: $50 \%$ grão úmido de sorgo ensilado e $50 \%$ grão úmido de milho ensilado; e

S100: 100\% grão úmido de sorgo ensilado.

A degradabilidade in situ da matéria seca e da fibra em detergente neutro do feno de aveia foi avaliada por intermédio da técnica de sacos de náilon, conforme descrito por Mehres \& Ørskov (1977). Foram utilizados sacos de náilon, com porosidade de $50 \mu \mathrm{m}$, medindo $10,0 \times 19,0 \mathrm{~cm}$, que abrigaram as amostras do alimento. Os sacos previamente identificados foram pesados em balança analítica de precisão e, então, receberam aproximadamente cinco gramas da amostra do feno a ser testado, com base na MS, a $65^{\circ} \mathrm{C}$, por 72 horas. Após serem amarrados, os sacos foram armazenados em câmara fria até o momento de uso.

Durante a incubação, os sacos foram presos à cânula ruminal através de um fio de náilon de $50 \mathrm{~cm}$. Estes sacos foram incubados durante $0 ; 6 ; 12 ; 24 ; 48$; 72 e 96 horas. Imediatamente após a retirada, nos tempos pré-determinados, eles foram lavados à mão e em água corrente até que o líquido de lavagem fluísse incolor, sendo então colocados em estufa a $65^{\circ} \mathrm{C}$ por 72 horas para posteriormente serem pesados e submetidos às análises bromatológicas. De forma a calcular as frações solúveis, a degradabilidade em tempo zero foi tomada mergulhando-se os sacos em recipiente contendo água à temperatura de $39^{\circ} \mathrm{C}$ durante 15 minutos (Cummins et al., 1983). As análises bromatológicas foram realizadas segundo AOAC (1985) e de FDN, segundo Goering \& Van Soest (1970). Os dados de degradabilidade foram ajustados pelo modelo de Ørskov \& McDonald (1979). As constantes a, b e c da equação exponencial foram utilizadas para calcular a degradabilidade potencial $(\mathrm{a}+\mathrm{b})$ e a degradabilidade efetiva (Ørskov et al., 1980).

As amostras de conteúdo ruminal foram coletadas em três pontos diferentes correspondentes ao antro e sacos ventrais anterior e posterior, por intermédio de uma bomba de vácuo. Foram retirados $500 \mathrm{~mL}$ de conteúdo ruminal, que foram devolvidos ao próventrículo, após colheita das devidas alíquotas. Exceto para as amostragens referentes à mensuração do volume e taxa de passagem de líquidos, todas as demais (AGVs, amônia e $\mathrm{pH}$ ) foram realizadas às 0 ; $2 ; 4 ; 6 ; 8 ; 10$ e 12 horas, após o arraçoamento matinal efetuado às $8 \mathrm{~h} 00$. A amostra referente a 0 hora foi coletada antes que os animais recebessem a primeira refeição. A segunda refeição foi oferecida somente às $16 \mathrm{~h}$, quando encerradas as amostragens.

Para determinação dos ácidos graxos voláteis (AGVs), uma alíquota de aproximadamente $100 \mathrm{~mL}$ de conteúdo ruminal foi centrifugada a $3.500 \mathrm{rpm}$ por 15 minutos; $1 \mathrm{~mL}$ do sobrenadante foi colocado em tubo de ensaio arrolhado, sendo adicionado $0,2 \mathrm{~mL}$ de ácido fórmico P.A., armazenando-se em congelador a $-20^{\circ} \mathrm{C}$ até o momento da análise. A concentração dos AGVs foi realizada através de cromatografia gasosa, segundo método preconizado por Erwin et al. (1961). Para tal foi utilizado um cromatógrafo a gás (modelo 9001, marca Finnigan) equipado com coluna 80/120 CarbopackTM B-DA*/4\% Carbowax ${ }^{\circledR} 20 \mathrm{M}$. $\mathrm{O}$ número de repetições por amostra foi aquele necessário para que a diferença entre leituras fosse inferior a $5 \%$.

Imediatamente após a coleta do líquido ruminal, $100 \mathrm{~mL}$ de fluido foram utilizados para determinação do $\mathrm{pH}$ em potenciômetro digital portátil, calibrados com soluções tampão de pH 4,0 e 7,0.

Para determinação da concentração de nitrogênio amoniacal, alíquotas de $2 \mathrm{~mL}$ de conteúdo ruminal foram colocadas em tubos de ensaios contendo $1 \mathrm{~mL}$ de solução de ácido sulfúrico $1 \mathrm{~N}$ e armazenadas sob refrigeração até a realização das análises. A determinação do nitrogênio amoniacal $\left(\mathrm{N}-\mathrm{NH}_{3}\right)$ foi realizada por colorimetria, segundo método proposto por Kulasek (1972) e adaptado por Foldager (1977).

A determinação do volume líquido e da taxa de passagem de líquidos pelo rúmen foi realizada por Polietilenoglicol de peso molecular 4.000 (PEG 4.000). Às $7 \mathrm{~h}$ do 21 o dia, após a retirada do último saco, foram introduzidos, através da fistula ruminal, $300 \mathrm{~g}$ de PEG (Carbowax 4.000, marca Synth) previamente diluídos em $250 \mathrm{~mL}$ de água, misturando-se em seguida o

R. Bras. Zootec., v.32, n.5, p.1266-1274, 2003 
marcador com o conteúdo ruminal manualmente. Amostras de conteúdo para determinações das concentrações de PEG foram tomadas às $0,1,3,6,9,12$ e 24 horas. A amostra referente ao tempo zero foi coletada antes da introdução do PEG, sendo a água e a refeição da manhã fornecidas imediatamente após a coleta da $1^{\mathrm{a}}$ hora, ou seja, às 8 h. O líquido ruminal foi centrifugado por 10 minutos a $3.500 \mathrm{rpm}$ no local da coleta e o sobrenadante armazenado sob refrigeração até a realização das análises. A determinação da concentração de PEG foi realizada segundo o método preconizado por Hyden (1956). A taxa de passagem de líquidos ou taxa eferente de fluxo, em porcentagem por hora, foi calculada por intermédio da regressão linear do logaritmo natural da concentração do PEG 4.000, em função do tempo, e o volume líquido ruminal, em litros, estimado pela extrapolação da concentração inicial (zero hora) e dosagem do marcador (300 g/animal).

Os dados foram analisados pelo programa Statistical Analysis System(SAS, 1985), sendo verificada a normalidade dos resíduos e a homogeneidade das variâncias. Os dados que não atenderam a estas premissas foram submetidos à transformação ou logarítmica $[\log (\mathrm{X}+1)]$ ou pela raiz quadrada $[\mathrm{RQ}(\mathrm{X}+1 / 2)]$. Os dados originais ou transformados, quando necessário, foram submetidos à análise de variância pelo procedimento General Linear Models (PROC GLM). As análises referentes à dinâmica líquida ruminal, degradabilidade in situ da MS e FDN do feno e os respectivos parâmetros da degradabilidade separaram como fontes de variação o efeito da cultura, estudandose os efeitos de tratamentos através de regressão polinomial. Os dados referentes aos AGVs, pH e concentrações de nitrogênio amoniacal no conteúdo ruminal foram analisados conforme descrito, porém adicionados do fator medidas repetidas no tempo, referentes aos diversos momentos de colheita entre as refeições. Tal análise foi realizada utilizado-se o comando REPEATED gerado pelo GLM do SAS. A análise por tempo somente foi realizada quando as interações entre tempo e tratamento foram significativas $(\mathrm{P}<0,05)$. Adotou-se um nível de significância de 5\% para todos os parâmetros analisados.

\section{Resultados e Discussão}

Na Tabela 2, são apresentadas as médias, probabilidades e coeficientes de variação da concentração total de AGVs (ácidos graxos voláteis) no líquido ruminal, porcentagem molar dos ácidos acético,

Tabela 2 - Concentração total de ácidos graxos voláteis (AGVs) no rúmen, porcentagens molares dos ácidos acético, propiônico e butírico, relação acético/propiônico (Ac/Prop), pH ruminal e concentração de $\mathrm{N}$-amoniacal (mg/ $\mathrm{dL}$ ) no líquido ruminal, nos diferentes tratamentos, com os respectivos coeficientes de variação (CV) e probabilidades estatísticas

Table 2 - Total volatile fatty acids (VFA) concentration in the rumen, molar percentage of acetate, propionate and butyrate acids, acetate/propionate ratio (Ac/Prop), ruminal $\mathrm{pH}$ and ammoniacal nitrogen concentration ( $\mathrm{mg} / \mathrm{dL})$, in different treatments, with the respective coefficients of variation (CV) and statistical probability

\begin{tabular}{|c|c|c|c|c|c|c|c|}
\hline \multirow[t]{3}{*}{$\begin{array}{l}\text { Variáveis } \\
\text { Variables }\end{array}$} & \multicolumn{4}{|c|}{$\begin{array}{c}\text { Médias } \\
\text { Means }\end{array}$} & \multicolumn{3}{|c|}{$\begin{array}{l}\text { Probabilidades } \\
\text { Probabilities } \\
\end{array}$} \\
\hline & \multirow[t]{2}{*}{ S 0} & \multirow[t]{2}{*}{ S 50} & \multirow[t]{2}{*}{ S 100} & \multirow[t]{2}{*}{$\mathrm{CV}$} & \multicolumn{2}{|c|}{$\begin{array}{c}\text { Tratamentos } \\
\text { Treatments } \\
\end{array}$} & \multirow[t]{2}{*}{$\begin{array}{c}\text { Trat* Tempo } \\
\text { Treat* Time }\end{array}$} \\
\hline & & & & & $\begin{array}{l}\text { Linear } \\
\text { Linear }\end{array}$ & $\begin{array}{c}\text { Desvio } \\
\text { Deviation } \\
\end{array}$ & \\
\hline $\begin{array}{l}\mathrm{AGVs}(\mathrm{mM}) \\
V F A(m M)\end{array}$ & 88,82 & 66,38 & 87,32 & 26,90 & $\mathrm{NS}$ & 0,0068 & 0,0041 \\
\hline $\begin{array}{l}\text { Acético } \\
\text { Acetate }\end{array}$ & 62,51 & 63,77 & 57,20 & 11,02 & NS & NS & NS \\
\hline $\begin{array}{l}\text { Propiônico } \\
\text { Propionate }\end{array}$ & 32,57 & 29,18 & 37,50 & 24,60 & NS & NS & 0,0582 \\
\hline $\begin{array}{l}\text { Butírico } \\
\text { Butyrate }\end{array}$ & 4,92 & 7,05 & 5,30 & 64,73 & NS & NS & 0,0832 \\
\hline $\begin{array}{l}\text { Ac/Prop } \\
\mathrm{pH}\end{array}$ & $\begin{array}{l}2,02 \\
6,23\end{array}$ & $\begin{array}{l}2,31 \\
6,49\end{array}$ & $\begin{array}{l}1,66 \\
6,23\end{array}$ & $\begin{array}{c}32,06 \\
6,28\end{array}$ & $\begin{array}{l}\text { NS } \\
\text { NS }\end{array}$ & $\begin{array}{l}\text { NS } \\
\text { NS }\end{array}$ & $\begin{array}{c}\mathrm{NS} \\
0,0005\end{array}$ \\
\hline $\begin{array}{l}\mathrm{N}-\mathrm{NH}_{3} \\
\mathrm{NH}_{3}-\mathrm{N}\end{array}$ & 7,78 & 6,70 & 6,26 & 87,00 & NS & NS & NS \\
\hline
\end{tabular}

NS = Não significativo.

NS = Not significant .

R. Bras. Zootec., v.32, n.5, p.1266-1274, 2003 
propiônico e butírico, relação acético/propiônico, $\mathrm{pH}$ ruminal e concentração de $\mathrm{N}$-amoniacal no rúmen, em função das silagens.

Foi observado efeito de desvio da linearidade para a concentração total de $\mathrm{AGVs}(\mathrm{P}<0,01)$. A dieta contendo $50 \%$ de silagem de milho e $50 \%$ de silagem de sorgo resultou em menor concentração de AGVs do que aquelas contendo $100 \%$ de silagem de sorgo ou de milho, apresentando porcentagens de redução de 23,98 e $25,27 \%$, respectivamente. Foi observada interação entre tempo e tratamento $(\mathrm{P}<0,01)$ para a concentração total de AGVs, sendo o efeito da substituição do milho úmido pelo sorgo úmido significativo nos tempos que se seguem com suas respectivas equações de regressão: à 0 hora: $\mathrm{Y}=69,8350$ $0,7464 \mathrm{x}+0,00745 \mathrm{x}^{2}\left(\mathrm{R}^{2}=0,34\right)$; às 10 horas: $\mathrm{Y}=93,7775-1,4758 \mathrm{x}+0,01279 \mathrm{x}^{2}\left(\mathrm{R}^{2}=0,80\right)$ e às 12 horas: $Y=91,0025-1,4706 x+0,01273 x^{2}\left(R^{2}=0,75\right)$, em que "Y" é a concentração total de AGVs e "x", o nível de sorgo úmido na dieta.

Os dados obtidos concordam parcialmente com os resultados apresentados por Stock et al. (1991), os quais observaram que animais alimentados somente com milhoúmido apresentaram maior concentração de AGVs totais, com aumento das concentrações de acetato, propionato e isobutirato, do que aqueles recebendo milho úmido misturado com sorgo seco laminado. Mesmo trabalhando com sorgo úmido ensilado no presente estudo, não foram observadas diferenças sobre porcentagens molares dos ácidos acético, propiônico e butírico, relação acético/propiônico, $\mathrm{pH}$ ruminal e concentração de $\mathrm{N}$-amoniacal no líquido ruminal, nos diferentes

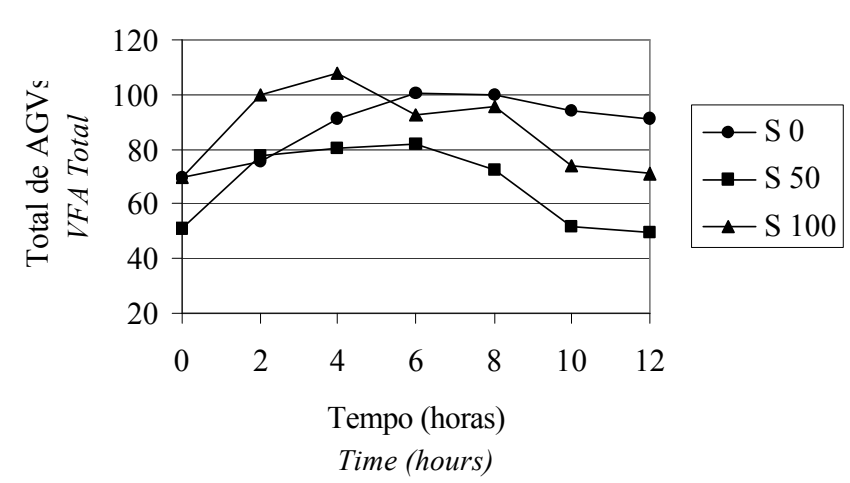

Figura 1 - Concentração de ácidos graxos voláteis totais (mM) em função do tempo, nos diferentes tratamentos.

Figure 1 - Total volatile fatty acids concentration (mM) in time, in different treatments.

R. Bras. Zootec., v.32, n.5, p.1266-1274, 2003 tratamentos.

A digestibilidade da matriz protéica do sorgo é menor que a do milho, o que é explicado pela maior proporção de endosperma periférico neste grão (Sniffen, 1980; Hale, 1973; Spicer et al., 1983). Contudo, para ensilagem do grão de sorgo úmido, o mesmo é colhido precocemente e utilizado, teoricamente, antes da matriz protéica estar completamente formada e solidificada, não ocorrendo interferência dessa matriz com a hidrólise do amido (Sullins et al., 1971; Hale et al., 1973), além disso, o maior teor de umidade favoreceria a fermentação no interior do silo, resultando em maior solubilização dos nutrientes, melhora da digestibilidade e do valor alimentar do grão (Gill et al., 1982; Simas, 1997). Essas teorias podem explicar o fato da dieta contendo $100 \%$ de sorgo úmido ter apresentado produção total de AGVs semelhantes às encontradas com $100 \%$ de milho úmido, mas não explica a menor produção de AGVs quando se utilizou a mistura dos grãos (50\%milho:50\%sorgo).

A Figura 2 mostra a porcentagem molar do ácido propiônico, em função do tempo, nos diversos tratamentos.

Houve interação tempo $\mathrm{x}$ tratamento $(\mathrm{P}<0,10)$ para as concentrações molares de ácido propiônico (Tabela 2), entretanto, na separação estatística dos efeitos da substituição do milho úmido pelo sorgo úmido em cada tempo não foram observadas diferenças.

A Figura 3 mostra a variação do $\mathrm{pH}$ ruminal, em função do tempo, nos diversos tratamentos.

Houve interação entre tempo e tratamento

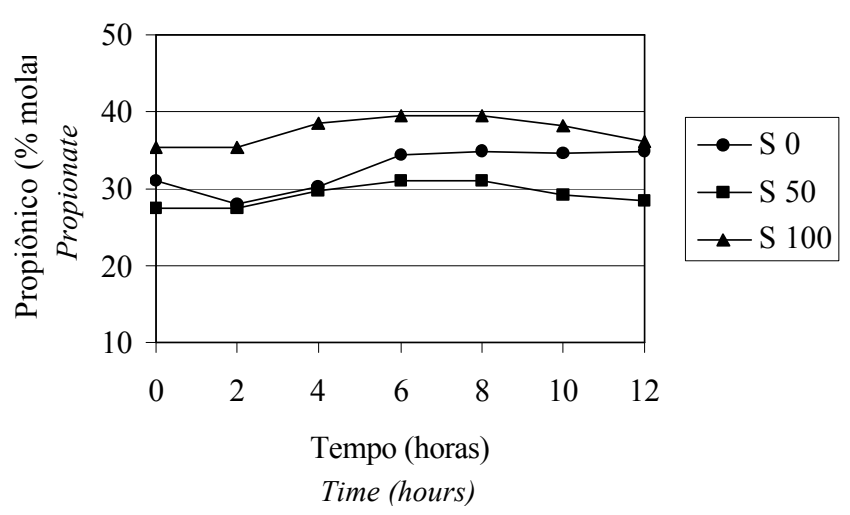

Figura 2 - Porcentagem molar do ácido propiônico em função do tempo, nos diferentes tratamentos.

Figure 2 - Molar percentage of propionate in time, in different treatments. 
$(\mathrm{P}<0,01)$ para os valores de $\mathrm{pH}$ ruminal. Às $10 \mathrm{e} 12 \mathrm{~h}$, observou-se maior valor de $\mathrm{pH}$ nas dietas contendo 50:50 de milho e sorgo úmidos. As equações de regressão encontradas foram: às $10 \mathrm{~h}$ : $\mathrm{Y}=6,075+0,0217 \mathrm{x}-0,00018 \mathrm{x}^{2}\left(\mathrm{R}^{2}=0,43\right)$ e às 12 horas: $\mathrm{Y}=6,225+0,0190 \mathrm{x}-0,00016 \mathrm{x}^{2}\left(\mathrm{R}^{2}=0,53\right)$, em que "Y" é o pH ruminal e " $\mathrm{x}$ ", o nível de sorgo úmido na dieta.

É possível que a associação dos grãos de milho e sorgo tenha favorecido a manutenção do $\mathrm{pH}$ ruminal, provavelmente devido às diferentes taxas de degra-

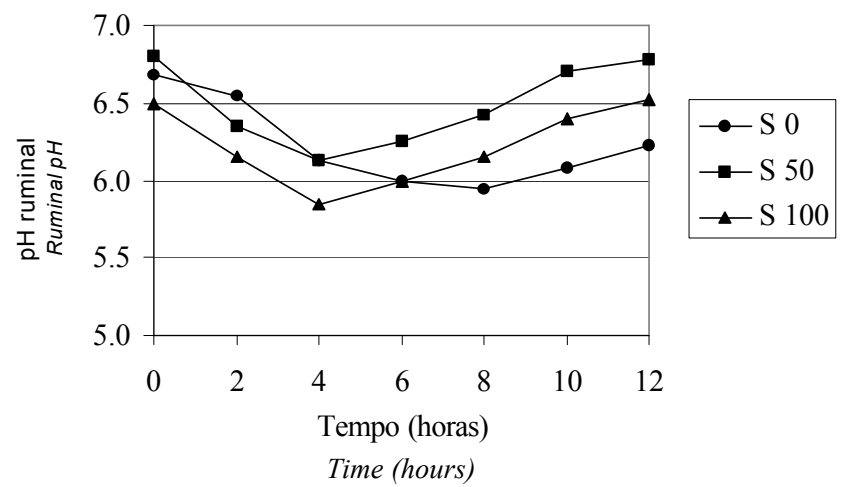

Figura 3 - Valores de pH ruminal, em função do tempo, nos diferentes tratamentos.

Figure 3 - Value of ruminal pH in time, in different treatments. dação dos grãos. Trabalhando com vacas secas e considerando uma taxa de passagem de 5\%/hora, a degradação da silagem de grão úmido de milho foi de $82 \%$, enquanto que para a silagem de grão úmido de sorgo foi de apenas 44\% (Passini, 2001). Entretanto, os valores médios de $\mathrm{pH}$ observados para as dietas com $100 \%$ sorgo ou $100 \%$ milho foram idênticos, não sendo significativo o efeito de tratamentos sobre o $\mathrm{pH}$ ruminal.

Com o uso do grão úmido de sorgo pode ocorrer maior sincronismo entre a liberação da energia e da proteína no rúmen, principalmente nas primeiras horas após alimentação, em virtude do aumento da disponibilidade do amido (com a ensilagem do grão úmido) e da degradação mais lenta da proteína do grão (matriz protéica), permitindo a incorporação da amônia liberada pelos microorganismos ruminais. Contudo, não foram observadas diferenças nas concentrações de $\mathrm{N}$-amoniacal entre os diferentes tratamentos (Tabela 2).

Constam na Tabela 3 os efeitos de cultura (milho ou sorgo) sobre os dados de dinâmica líquida ruminal.

Não foram observadas diferenças estatísticas sobre os parâmetros de fluxo e volume de líquidos do rúmen para os diferentes tratamentos estudados. Este fato pode ser explicado pelo consumo de matéria seca, o qual não diferiu entre os tratamentos, sendo em média de $11,16 \mathrm{~kg} /$ dia ou $1,9 \%$ do peso vivo.

$\mathrm{O}$ valor médio de volume líquido ruminal total

Tabela 3 - Efeitos do milho ou sorgo sobre o volume líquido ruminal total (VOL), em litros; volume líquido em função do peso vivo (VLPV), em porcentagem; taxa de passagem de líquidos (TX), em porcentagem por hora; fluxo de passagem de líquidos por dia (FL), em litros, e fluxo de passagem de líquidos por dia por quilo de matéria seca consumida (FLMS), com os respectivos coeficientes de variação (CV) e probabilidades estatísticas

Table 3 - Effects of corn or sorghum on total ruminal liquid volume (RLV), in liters; liquid volume per body weight (LVBW), in percentage; liquid passage ratio (LPR), in percentage per hour; liquid passage flow per day (LPF), in liters; and liquid passage flow per kilogram of daily dry matter intake (LPDM), with the respective coefficients of variation (CV) and statistical probability

\begin{tabular}{|c|c|c|c|c|c|c|c|}
\hline \multirow[t]{2}{*}{$\begin{array}{l}\text { Variáveis } \\
\text { Variables }\end{array}$} & \multicolumn{3}{|c|}{$\begin{array}{c}\text { Tratamentos } \\
\text { Treatments }\end{array}$} & \multirow[b]{2}{*}{$\begin{array}{l}\text { Médias } \\
\text { Means }\end{array}$} & \multirow[b]{2}{*}{ CV } & \multicolumn{2}{|c|}{$\begin{array}{c}\text { Probabilidades } \\
\text { Probabilities }\end{array}$} \\
\hline & S0 & $\mathrm{S} 50$ & S 00 & & & $\begin{array}{l}\text { Linear } \\
\text { Linear }\end{array}$ & $\begin{array}{c}\text { Desvio } \\
\text { Deviation }\end{array}$ \\
\hline $\begin{array}{l}\text { VOL } \\
R L V\end{array}$ & 58,75 & 63,87 & 56,58 & 59,73 & 27,13 & $\mathrm{NS}$ & NS \\
\hline $\begin{array}{l}\text { VLPV } \\
L V B W\end{array}$ & 10,55 & 11,16 & 9,75 & 10,48 & 35,64 & NS & NS \\
\hline $\begin{array}{l}\mathrm{TX} \\
L P R\end{array}$ & 6,55 & 6,51 & 6,75 & 6,60 & 21,71 & NS & NS \\
\hline $\begin{array}{l}\mathrm{FL} \\
L P F\end{array}$ & 89,57 & 95,77 & 90,33 & 91,89 & 22,72 & NS & NS \\
\hline $\begin{array}{l}\text { FLMS } \\
L P D M \\
\end{array}$ & 9,45 & 8,58 & 8,29 & 8,77 & 19,75 & NS & NS \\
\hline
\end{tabular}

R. Bras. Zootec., v.32, n.5, p.1266-1274, 2003 
encontrado neste estudo (59,7 litros), com animais pesando $584 \mathrm{~kg}$ e consumindo $11 \mathrm{~kg} \mathrm{MS} / \mathrm{dia}$, em média, foi semelhante aos resultados obtidos por Jacques et al. (1987) com novilhos pesando $227 \mathrm{~kg}$ (56,7 litros); porém, foi inferior aos apresentados por Yang \& Russell (1993) trabalhando com vacas pesando $685 \mathrm{~kg}$ (81,5 litros) e superior aos encontrados por Clary et al. (1993), em novilhos com $430 \mathrm{~kg}$ (46,6 litros).

A taxa de passagem de líquidos neste estudo foi, em média, $6,6 \%$ /hora, ficando próxima aos valores de $6,5 \% /$ h (Clary et al., 1993) e 7,0\%/h (Yang \& Russell, 1993). Alguns estudos mostram valores bastante superiores, como $8,5 \% / \mathrm{h}$ (Rodriguez et al., 1986), 9,7\%/h (Branine \& Galyean, 1990) e 10,9\%/h (Roges \& Davis, 1982). As menores taxas de passagem observadas podem estar relacionadas à alta proporção de concentrado na dieta ( $80 \%$ da MS), visto que, geralmente a taxa de diluição da fase líquida é maior em animais recebendo dietas volumosas quando comparadas a dietas concentradas (Chalupa, 1977). Rodrigues (1996) observou aumento de $23,9 \%$ na taxa de passagem de líquidos por quilo de MS consumida ao aumentar a proporção de volumoso na dieta de 40 para $70 \%$.

Os valores médios da degradabilidade ruminal in situ da MS e da FDN do feno de aveia nos diferentes tratamentos, coeficientes de variação $(\mathrm{CV})$ e probabilidades estatísticas são mostrados nas Tabelas 4 e 5.

Não foram observados efeitos da dieta sobre a degradabilidade da MS e FDN do feno nos diferentes tratamentos. Segundo Coelho da Silva e Leão (1979), os valores de $\mathrm{pH}$ inferiores a 6,0 podem acarretar diminuição da atividade dos microorganismos fibrolíticos, sendo que para Mertens (1992) a digestão da fibra declinaria em $\mathrm{pH}$ abaixo de 6,7 e para Ørskov (1982) e Mould et al. (1983), abaixo de 6,2. No presente estudo, embora a proporção de concentrado na dieta tenha atingido $80 \%$ da MS, o pH 6,0 foi o menor valor observado nas médias e não interferiu na degradação do alimento volumoso.

Considerando todas as taxas de passagem estimadas (2, 5 e $8 \%)$, pode-se observar que, embora não difiram estatisticamente, os valores de degradação da MS do feno foram, em média, 3\% menores nas dietas contendo $100 \%$ de sorgo em relação àquela com $100 \%$ de milho úmido. Os maiores valores observados para a degradabilidade da MS do feno foram nas dietas contendo 50:50 de sorgo e milho, novamente sugerindo possível melhora no ambiente ruminal com a associação dos grãos na dieta.

Da mesma forma, os valores de degradação da FDN do feno foram superiores nas dietas onde se associaram os grãos (50:50 milho e sorgo). Embora não tenha sido estatísticamente diferente, a porcentagem de aumento com a associação dos grãos (média das três taxas de passagem) foi de 8,4 e $7 \%$ em relação às dietas contendo $100 \%$ de sorgo e $100 \%$ de milho, respectivamente.

Tabela 4 - Degradabilidade ruminal in situ da matéria seca do feno de aveia para os diferentes tratamentos, coeficientes de variação (CV) e probabilidades estatísticas ${ }^{1}$

Table 4 - Ruminal in situ degradability of oat hay dry matter for different treatments, with the respective coefficient of variation (CV) and statistical probability

\begin{tabular}{|c|c|c|c|c|c|c|c|}
\hline \multirow[t]{2}{*}{$\begin{array}{l}\text { Degradação ruminal } \\
\text { Ruminal degradability }\end{array}$} & \multicolumn{3}{|c|}{$\begin{array}{l}\text { Tratamentos } \\
\text { Treatments }\end{array}$} & \multirow[b]{2}{*}{$\begin{array}{l}\text { Médias } \\
\text { Means }\end{array}$} & \multirow[b]{2}{*}{$\mathrm{CV}$} & \multicolumn{2}{|c|}{$\begin{array}{c}\text { Probabilidades } \\
\text { Probabilities }\end{array}$} \\
\hline & S0 & $\mathrm{S} 50$ & S100 & & & $\begin{array}{l}\text { Linear } \\
\text { Linear }\end{array}$ & $\begin{array}{c}\text { Desvio } \\
\text { Deviation } \\
\end{array}$ \\
\hline $\mathrm{a}$ & 15,54 & 16,48 & 17,08 & 16,37 & 9,29 & NS & NS \\
\hline b & 50,49 & 47,69 & 51,96 & 50,05 & 8,73 & NS & NS \\
\hline $\mathrm{c}$ & 0,034 & 0,036 & 0,026 & 0,032 & 23,71 & NS & NS \\
\hline De $2 \%$ & 47,11 & 47,22 & 45,90 & 46,74 & 7,08 & NS & NS \\
\hline De $5 \%$ & 35,80 & 36,57 & 34,60 & 35,66 & 8,15 & NS & NS \\
\hline De $8 \%$ & 30,47 & 31,41 & 29,70 & 30,52 & 8,03 & NS & NS \\
\hline $\mathrm{Dp}$ & 66,03 & 64,17 & 69,04 & 66,41 & 5,43 & NS & NS \\
\hline
\end{tabular}

1 a, b e c referem-se aos parâmetros de Ørskov \& McDonald (1979). De = degradabilidade efetiva para taxas de passagem iguais a 0,$02 ; 0,05$ e 0,08 por hora. Dp = degradabilidade potencial.

$1 \mathrm{a}, \mathrm{b}$ and c are Ørskov \& McDonald (1979) parameters. De =effective degradability for passage rates of .02, .05, and .08 per hour. $P D=$ potencial degradability.

R. Bras. Zootec., v.32, n.5, p.1266-1274, 2003 
Tabela 5 - Degradabilidade ruminal in situ da FDN do feno de aveia para os diferentes tratamentos, coeficientes de variação (CV) e probabilidades estatísticas ${ }^{1}$

Table 5 - Ruminal "in situ" degradability of oat hay NDF for different treatments, with the respective coefficients of variation (CV) and statistical probability

\begin{tabular}{|c|c|c|c|c|c|c|c|}
\hline \multirow[t]{2}{*}{$\begin{array}{l}\text { Degradação ruminal } \\
\text { Ruminal degradability }\end{array}$} & \multicolumn{3}{|c|}{$\begin{array}{l}\text { Tratamentos } \\
\text { Treatments }\end{array}$} & \multirow[b]{2}{*}{$\begin{array}{l}\text { Médias } \\
\text { Means }\end{array}$} & \multirow[b]{2}{*}{$\mathrm{CV}$} & \multicolumn{2}{|c|}{$\begin{array}{c}\text { Probabilidades } \\
\text { Probabilities }\end{array}$} \\
\hline & S0 & $\mathrm{S} 50$ & $\mathrm{~S} 100$ & & & $\begin{array}{l}\text { Linear } \\
\text { Linear }\end{array}$ & $\begin{array}{c}\text { Desvio } \\
\text { Deviation } \\
\end{array}$ \\
\hline A & $-1,95$ & $-0,50$ & $-0,06$ & $-0,79$ & $-269,46$ & NS & NS \\
\hline b & 60,16 & 55,33 & 62,26 & 59,25 & 10,31 & NS & NS \\
\hline c & 0,030 & 0,033 & 0,023 & 0,028 & 24,70 & NS & NS \\
\hline De $2 \%$ & 33,84 & 33,88 & 32,59 & 33,44 & 12,96 & NS & NS \\
\hline De $5 \%$ & 20,40 & 21,46 & 19,25 & 20,37 & 17,38 & NS & NS \\
\hline De $8 \%$ & 14,31 & 15,64 & 13,70 & 14,55 & 20,22 & NS & NS \\
\hline $\mathrm{Dp}$ & 58,21 & 54,83 & 62,32 & 58,46 & 9,03 & NS & $0,0886 *$ \\
\hline
\end{tabular}

$P D$

1 a, $b$ e $c$ referem-se aos parâmetros de Ørskov \& McDonald (1979). De = degradabilidade efetiva para taxas de passagem iguais a 0,$02 ; 0,05$ e 0,08 por hora. $\mathrm{Dp}=$ degradabilidade potencial.

* Equação de regressão: $Y=58,215-0,1763 x+0,0022 x^{2}\left(R^{2}=0,37\right)$, em que " $Y$ " é a degradabilidade potencial da FDN do feno de aveia e " $x$ ", a porcentagem de sorgo úmido.

$1 \mathrm{a}, b$ and $c$ are Ørskov \& McDonald (1979) parameters. De =effective degradability for passage rates of $.02, .05$ and .08 per hour. $P D=$ potencial degradability. * Regression equation: $Y=58.215-0.1763 x+0.0022 x^{2}\left(R^{2}=0.3665\right)$, where " $Y$ " is the potencial degradability of oat hay NDF and " $x$ " is percentage of high moisture sorghum.

\section{Conclusões}

Os parâmetros de fermentação ruminal e a degradabilidade do volumoso não foram influenciados pela associação dos grãos úmidos de milho e de sorgo na dieta.

Nas condições deste estudo, existem poucas evidências de que o uso associado dos grãos úmidos de milho e de sorgo na dieta possa favorecer o ambiente ruminal.

\section{Agradecimento}

Aos funcionários Everson e Gilmar, pelo cuidado com os animais, e aos técnicos de laboratório Simi e Gilson, pela condução das análises laboratoriais.

\section{Literatura Citada}

ASSOCIATION OF OFFICIAL ANALYTICAL CHEMISTSAOAC. Official methods of analysis. 13.ed. Washington, D.C.: $1985.1141 \mathrm{p}$.

BRANINE, M.E.; GALYEAN, M.L. Influence of grain and monensin supplementation on ruminal fermentation, intake, digesta kinetcs and incidence and severity of frothy bloat in steers grazing winter wheat pasture. Journal of Animal Science, v.68, n.3, p.1139-1150, 1990.

CHALUPA, W. Manipulating rumen fermentation. Journal of Animal Science, v.45, n.3, p.585-599, 1977.

CLARY, E.M.; BRANDT, R.T.; HARMON, D.L. et al. Supplemental fat and ionophores in finishing diets: feedlot performance and ruminal digesta kinetics in steers. Journal of Animal Science, v.71, n.11, p.3115-3123, 1993.
COELHO DA SILVA, J.F.; LEÃO, M.I. Fundamentos de nutrição de ruminantes. Piracicaba: Livroceres, 1979. 380p.

CUMMINS, K.A.; NOCEK, J.E.; POLAN, C.E. et al. Nitrogen degradability and microbial protein synthesis in calves fed diets of varying degradability by the bag technique. Journal of Dairy Science, v.66, n.11, p.2356-2364, 1983.

ERWIN, E.S.; MARCO, G.J.; EMERY, E.M. Volatile fatty acid analyses of blood and rumen fluid by gas chromatography. Journal of Dairy Science, v.44, n.9, p.1768-1771, 1961.

FOLDAGER, J. Protein requirement and non protein nitrogen for high producing cow in early lactation. $\mathrm{Ph}$. $\mathrm{D}$. thesis, East Lasing - Michigan State University, 1977.

GOERING, H.K.; Van SOEST, P.J. Forage fiber analysis (Apparatus, reagents, procedures and some applications). Agriculture Handbook, 379, Agricultural Research Service, Washington D.C.: 1970. 19p.

HALE, W.H. Influence of processing on the utilization of grain (starch) by ruminants. Journal of Animal Science, v.37, p.1075-80, 1973.

HENDRIX, D.L. Rapid extraction and análisis of nonstructural carbohydrates in plant tissues. Crop Science, v.33, p.1306-1311, 1993.

HYDEN, S. A turbidometric method for the determination of higher polyethylene glycols in biological materials. Lantbruks-Hogskol, v.22, p.139-145, 1956.

JACQUES, K.A.; COCHRAN, R.C.; CORRAH, L.R. et al. Influence of lasalocid level on forage intake, digestibility, ruminal fermentation liquid flow and performance of beef cattle grazing winter range. Journal of Animal Science, v.65, n.3, p.777-785, 1987.

KULASEK, G. A micromethod for determination of urea in plasma, whole blood and blood cells using urease and phenol reagent. Polskie Archiwum Weterynaryjne, v.15, n.4, p.801-810, 1972.

MEHRES, A.Z.; ØRSKOV, E.R. A study of the artificial fiber bag technique for determining the digestibility of feeds in the rumen. Journal of Agriculture Science, v.88, p.645-650, 1977.

R. Bras. Zootec., v.32, n.5, p.1266-1274, 2003 
MERTENS, D. R. Analysis of fiber in feeds and its use in feed evaluation and ration formulation. In: SIMPÓSIO INTERNACIONAL DE RUMINANTES, 1992, Lavras, MG. Anais...Lavras:Universidade Federal de Lavras, 1992. p.1-32.

MOULD, F.L.; ØRSKOV, E.R.; MANN, S.O. Associative effects of mixed feeds. 2. The effect of dietary additions of bicarbonate salts on the voluntary intake and digestibility of diets containing various proportions of hay and barley. Animal Feed Science and Technology, v.10, p.15-25, 1983.

NATIONAL RESEARCH COUNCIL-NRC. Nutrient requirements of beef cattle. 7.ed. Washington, National Academy Press, 1996. 242p.

ØRSKOV, E.R. Protein nutrition in ruminants. London: Academic Press, 1982. 160p.

ØRSKOV, E.R.; McDONALD, I. The estimation of protein degradability in the rumen fron incubation measurements weighted according to rate of passage. Journal of Agriculture Science, v.92, p.499-503, 1979.

ØRSKOV, E.R.; HOVELL, F.D.Deb.; MOULD, F. Uso de la tecnica de la bolsa de nylon para la avaluacion de los alimentos. Production Animal Tropics, v.5, n.3, p.213-233, 1980.

OWENS, F.N.; SECRIST, D.S.; JEFF HILL, W. et al. The effect of grain source and grain processing on performance of feedlot cattle: a review. Journal of Animal Science, v.75, p.868-79, 1997.

PASSINI, R. Processamento de grãos de milho e de sorgo e níveis de proteína sobre a digestibilidade, desempenho e características de carcaça de bovinos superprecoce. Botucatu: Universidade Estadual Paulista, 2001. 54p. Tese (Doutorado) - Universidade Estadual Paulista, 2001.

RODRIGUES, P.H.M. Efeitos da lasalocida sódica e proporção volumoso/concentrados sobre a fermentação ruminal e degradabilidade in situ do farelo de soja e do feno Coast Cross (Cynodon dactylon). Pirassununga: Universidade de São Paulo, 1996. 135p. Dissertação (Mestrado) - Universidade de São Paulo, 1996.

RODRIGUEZ, S.L.; CRAIG, W.M.; HEMBRY, F.G. Changes in ruminal concentrations of microbial ammonia and amino acids due to monensin and time. Journal of Animal Science, v.63, n.6, p.1990-1995, 1986.
ROGERS, J.A.; DAVIS, C.L. Rumen volatile fatty acid production and nutrient utilization in steers fed a diet supplemented with sodium bicarbonate and monensin. Journal of Dairy Science, v.65, n.6, p.944-952, 1982.

ROSSI Jr., P.; PEREIRA, J.R.A. Manual prático de avaliação nutricional de alimentos. Piracicaba: Fundação de Estudos Agrários Luiz de Queiroz, 1995. 34p.

SAS INSTITUTE. Statistical Analysis System. 5.ed. Cary: 1985.

SNIFFEN, C.J. The use of by-pass protein in ration formulation. In: AMERICAN FEED MANUFACTURE ASSOCIATION NUTRITION COUNCIL, 40., New York. Proccedings... New York: 1980. p.40.

SPICER, L.; THEURER, B.; YOUNG, M.C. Ruminal e postruminal utilization of protein feed grains by beef steers. Journal of Animal Science, v.57 (supl.1), p.470, 1983.

STOCK, R.A.; SINDT, M.H.; CLEALE IV, R.M. et al. Highmoisture corn utilization in finishing cattle. Journal of Animal Science, v.69, p.1645-1656, 1991.

SULLINS, R.D.; ROONEY, L.W.; RIGGS, J.K. Physical changes in the kernel during reconstitution of sorghum grain. Cereal Chemists, v.48, p.567, 1971.

Van SOEST, P.J. Nutritional ecology of the ruminant. 2.ed. London: Cornell University Press, 1994. 476p.

YANG, C.M.J.; RUSSELL, J.B. The effect of monensin supplementation on ruminal ammonia accumulation in vivo and the numbers of amino acid-fermenting bacteria. Journal of Animal Science, v.71, n. 12, p.3470-3476, 1993.

ZINN, R.A. Influence of flake density on the comparative feeding value of steam-flaked corn for feedlot cattle. Journal of Animal Science, v.67, p.767, 1990. 